\title{
O IMPACTO DA MIGRAÇÃO DAS EMPRESAS PARA OS NIIVEIS DIFERENCIADOS DE GOVERNANÇA CORPORATIVA DA BM\&F BOVESPA SOBRE O RISCO E O RETORNO DE SUAS AÇÕES
}

\author{
THE IMPACT OF THE MIGRATION OF \\ BUSINESSES TO THE DIFFERENTIATED LEVELS OF \\ BM\&F BOVESPA'S CORPORATE GOVERNANCE OVER \\ THE AND RETURN OF ITS SHARES
}

Recebido 27/02/2011

Aceito $16 / 10 / 2011$

Ricardo Luiz Menezes da Silva ${ }^{1}$ Paula Carolina Ciampaglia $\mathrm{Nardi}^{2}$

Tabajara Pimenta Junior ${ }^{3}$

\section{RESUMO}

A transparência das informações é importante para se ter uma diminuição na assimetria das mesmas. Quanto mais informações de qualidade há sobre o negócio ou desempenho econômico e financeiro de determinada empresa, teoricamente, mais se pode esperar uma diferente percepção do risco por parte do investidor. O objetivo deste estudo foi verificar se a iniciativa das empresas em aderir aos Níveis Diferenciados de Governança Corporativa da BM\&F BOVESPA impacta tanto no risco quanto no retorno dos preços de fechamento de suas ações. Para isso, foram utilizados os retornos diários de 252 dias antes e após a adesão das empresas aos NDGC. Foram feitos os testes de Kolmogorov-Smirnov para análise da normalidade, o teste paramétrico de médias emparelhadas e o teste não paramétrico de Wilcoxon para medidas de risco absoluto (desvio-padrão) e relativo (beta), além de retorno. Foram analisados os comportamentos dos papéis de 48 empresas. Os resultados mostraram que as médias dos retornos das ações empresariais não apresentaram diferenças significativas antes e após a data de adesão aos NDGC. Por outro lado, as proxies de risco apresentaram-se significativamente diferentes.

Palavras-chave: Governança Corporativa; Mercado de Capitais; Risco e Retorno

\footnotetext{
1 Bacharel em Ciências Contábeis e Mestre em Controladoria e Contabilidade pela FEARP-USP. Atualmente é doutorando pelo Programa de Pós-Graduação em Ciências Contábeis (PPGCC) da FEA/USP com interesse na área de Contabilidade e Mercado Financeiro e professor assistente pela FEARP-USP.E-mail: rImsilva@terra.com.br

2 Bacharel em Ciências Contábeis e Mestre em Controladoria e Contabilidade pela FEARP-USP. Atualmente é professora assistente pela FEARP-USP. E-mail: paula.nardi@yahoo.com.br

3 Doutor em Administração pela FEA-USP. Atualmente é professor pela FEARP-USP. E-mail: taba.jr@terra.com.br
} 


\section{ABSTRACT}

The transparency of information is important to diminish the asymmetry of information. The more quality information there is about the business, or financial and economic performance of a certain company, theoretically, the more one can expect a different perception of risk by the investor. The aim of this study was to verify whether the initiative of the companies to adhere to BM\&F BOVESPA's Differentiated Levels of Corporate Governance impacts both at risk and return of the closing price of its shares. For that, daily returns of 252 days before and after the accession of companies to NDGC were used. Over the measures of absolute risk (standard deviation) and relative risk (beta), and return, Kolmogorov-Smirnov tests were made in order to analyze normality, as well as parametric test of paired means and Wilcoxon's non-parametric test. The behaviors of the roles of 48 companies were analyzed. The results showed that the means of the returns of the companies' shares showed no significant differences before and after the date of accession to NDGC. Moreover, the risk proxies were significantly different.

Keywords: Corporate Governance; Capital Markets; Risk and Return

\section{INTRODUÇÃO}

A questão da harmonização de interesses dentro de uma empresa não é tarefa simples, como salienta Andrade e Rossetti (2004, p.324), principalmente quando ocorre uma separação entre propriedade e gestão. As decisões dos gestores nem sempre estão alinhadas com os interesses dos acionistas, o que gera o denominado "Conflito de Agência". Nessa realidade, maior atenção passa a ser dada para questões de boas práticas de governança corporativa.

Segundo os mesmos autores, a existência de contratos incompletos e comportamentos imperfeitos abre espaço para a divergência de interesses entre acionistas e administradores, ocasionando custos atribuídos ao oportunismo destes.

Nesse contexto, mecanismos que almejam melhores práticas de governança corporativa foram desenvolvidos, como: divulgação de informações trimestrais e de fluxo de caixa (buscando maior transparência); acordos de tag along (com o intuito de um tratamento mais equitativo entre os acionistas); conselho independente, entre outros. O objetivo desses mecanismos é reduzir os conflitos de agência e contribuir com uma série de benefícios como: aumentar a liquidez das ações, obter menor custo de captação, melhorar sua imagem institucional, etc.

No Brasil, a BM\&F BOVESPA - Bolsa de Valores, Mercadorias e Futuros - criou os Níveis Diferenciados de Governança Corporativa (NDGC) com o intuito de estabelecer certos mecanismos de boas práticas para reduzir, entre outras coisas, a assimetria de informação e para dar maior segurança aos acionistas e investidores.

A transparência é um dos pilares da governança corporativa que trata da qualidade da informação prestada ao usuário, principalmente para que este tenha melhor subsídio para sua tomada de decisão. Portanto, informações de qualidade a respeito do desempenho e da situação econômico-financeira da empresa podem influenciar na percepção de risco do investidor ao analisar a situação de uma companhia.

Algumas pesquisas internacionais [Botosan (1997), Gode e Mohanram (2001), Hail (2002)] observaram uma relação significativa entre maior disclosure e a redução no custo de capital próprio. Assim, se esse custo é menor, é porque os acionistas ou investidores sentemse mais seguros frente às empresas, o que ocorre pela maior transparência percebida nas informações divulgadas.

Por outro lado, algumas pesquisas nacionais, como Carvalho (2002), Macedo, Mello e Tavares Filho (2006), e Kitagawa et al (2007), encontraram resultados diversos, ora detectando significância na relação, ora não. 
O levantamento bibliográfico, retratado na seção 2 deste trabalho também revelou a existência de estudos relacionando boas práticas de governança corporativa com risco e retorno das empresas. Os estudos de Macedo, Mello e Tavares Filho (2006) e Malacrida e Yamamoto (2006) relacionaram a adesão aos NDGC com o risco associado às variações dos retornos das cotações das ações das empresas listadas na BM\&F BOVESPA. Os estudos de Pedreira e Santos (2006), Batistella et al (2004), Sirqueira, Kalatzis e Toledo (2007), Camargos e Barbosa (2006), e Healy, Hutton e Palepu (1999) exploraram a relação entre a adesão das empresas aos NDGC com o retorno medido pela variação das cotações das ações.

Portanto, para contribuir com as pesquisas nessa linha, este estudo foi desenvolvido visando a verificar se a iniciativa das empresas em aderir aos níveis diferenciados de governança corporativa impacta tanto no risco quanto no retorno de tais companhias.

O problema de pesquisa que se propõe é: empresas brasileiras que aderiram aos níveis diferenciados de governança corporativa da BM\&F BOVESPA tiveram a mudança no comportamento de risco e o retorno medidos na variação das cotações de suas ações listadas?

Dessa forma, as hipóteses propostas foram:

$\mathrm{H}_{0,1}$ : O retorno das empresas que aderiram aos NDGC não apresenta diferença após a adesão aos NDGC, aos NDGC

$\mathrm{H}_{1,1}$ : O retorno das empresas que aderiram aos NDGC apresenta diferença após a adesão

$\mathrm{H}_{0,2}: \mathrm{O}$ risco das empresas que aderiram aos NDGC não apresenta diferença após a adesão aos NDGC, aos NDGC.

$\mathrm{H}_{1,2}$ : O risco das empresas que aderiram aos NDGC apresenta diferença após a adesão

Para tanto, o artigo apresenta a seguinte estrutura: além desta introdução, na seção 2, é apresentada a revisão bibliográfica; na seção 3, está presente o método utilizado; na seção 4, apresentam-se os resultados; e, na seção 5, são feitas as considerações finais.

\section{REVISÃO DA LITERATURA}

Esta seção traz aspectos teóricos que fundamentam a pesquisa, sendo uma revisão sobre os antecedentes do tema ou marco teórico, bem como uma explanação sobre o que é governança corporativa e o desenvolvimento de novos mecanismos no Brasil; conceito de risco; e estudos de âmbito nacional e internacional que exploram o tema tratado neste artigo.

\subsection{Antecedentes}

Em 1776, segundo Okimura (2003, p.10), a questão da separação entre propriedade e controle foi primeiramente tratada por Adam Smith. Em seguida, o assunto foi abordado por Berle e Means (1932) e por Jensen e Meckling (1976), que retomam essa questão.

Jensen e Meckling (1976) salientam que o ponto central do conflito de agência é a relação entre duas partes, as quais ocupam funções diferentes, sendo que uma depende das ações da outra (principal contrata o agente e passa a depender de suas ações). Nesse cenário, e sabendo-se que as pessoas são maximizadoras de sua utilidade, é grande a possibilidade de se deparar com comportamentos oportunistas desses agentes. Eles podem omitir a verdadeira realidade da empresa em busca de qualquer benefício pessoal, nem que para isso tenha que expropriar os interesses da parte contratante, ou seja, do acionista. Isso ocorre, pois é ilusório 
acreditar que o agente irá fazer o serviço que lhe cabe tão bem em favor do acionista, como se esse serviço fosse para atender suas expectativas.

Decorre que os problemas de agência surgem praticamente quando o bem-estar de uma parte é dependente de ações de outras partes, as quais podem ter interesses conflitantes com a primeira, fazendo com que tomem decisões caracterizadas por moral hazard, ou risco moral, como se refere Carvalho (2002, p.19). O risco moral é característica das tomadas de decisões de um agente em detrimento às vontades do principal.

Além do risco moral, mas intimamente ligado a ele, está a questão da assimetria informacional, a qual é uma alavanca para o conflito de agência. A assimetria de informações significa, segundo Hendrinsen e VanBreda (1999), que nem todas as informações são conhecidas por ambas as partes (agentes e principais), ou seja, quando uma parte possui informações em condições distintas daquelas da outra parte. Tomando-se como exemplo a relação gestor/ acionista, o gestor acaba por ter informações diferentes sobre os negócios da empresa - suas estratégias, informações sobre o orçamento, entre tantas outras - em relação ao acionista. Assim, pode-se dizer que, quem tem mais informação está em melhor posição para obter um retorno desejado e incorrer em menor risco.

Hillbrecht (1999, p. 86) explica o conceito: "Informação assimétrica (em mercados financeiros) surge quando uma das partes envolvidas em uma transação não tem toda informação disponível à outra, o que a impede de tomar uma decisão correta com respeito à transação".

Dentro desse contexto de conflito de agência e assimetria informacional, novos mecanismos de governança corporativa passaram a ser desenvolvidos, com o objetivo de reduzir esses conflitos e a assimetria informacional, o que, por sua vez, tenta diminuir qualquer comportamento oportunista que o agente possa vir a ter. Andrade e Rossetti (2004, p.89) corroboram o exposto anteriormente e afirmam que o conflito de agência, seja ele gerado pelo oportunismo dos gestores ou pela dispersão do controle, foi a razão fundamental do despertar de novas práticas de governança corporativa, a qual passou a referenciar mecanismos a serem exigidos pelos acionistas para corrigir desvios de conduta e deficiências gerenciais, no que se refere à manipulação de resultados, bem como maior proteção aos acionistas minoritários em se tratando do conflito proveniente da separação entre propriedade e controle.

Além disso, com a criação da governança corporativa e seus mecanismos, espera-se que, de acordo com Vasconcellos (2002, p.19), as "Boas práticas de Governança Corporativa aumentem a eficiência da gestão, reduzam o custo de capital, atraiam novos investimentos e possibilitam o crescimento da empresa".

\subsection{Governança Corporativa}

A governança corporativa é fundamentada em quatro princípios básicos, segundo Andrade e Rossetti (2004), são eles: a) fairness: refere-se ao tratamento justo aos acionistas; b) accountability: aborda a questão da prestação de contas de forma responsável; c) compliance: compreende a conformidade no cumprimento de normas reguladoras; e d) disclosure: refere-se à transparência das informações, especialmente das de alta relevância, que impactam os negócios e que envolvem riscos.

Assim, tomando como base o pilar da transparência das informações, segundo Lanzana (2004), uma evidenciação clara é uma forma importante para os gestores da empresa se comunicarem com acionistas, mercado e sociedade. Por meio desse recurso, pode-se ter uma diminuição na assimetria das informações, pois, conforme define Bushman et al (2001), transparência é disponibilizar informações relevantes e confiáveis sobre a empresa - seu 
desempenho, sua situação financeira, seus investimentos, sua governança, seus valores - e, até mesmo, sobre os riscos incorridos pela instituição.

Dessa forma, quanto mais informações de qualidade há sobre o negócio, como o desempenho econômico e financeiro de determinada empresa, espera-se uma percepção de risco do investidor mais adequada, se comparado ao cenário de informações insuficientes.

Diamond e Verrechia (1991) verificaram que a obrigação contratual exigindo que as empresas evidenciem mais informação do que a lei determina pode resultar em aumento de liquidez de suas ações e, consequentemente, em redução de custo de capital. A justificativa é que, revelando informações públicas para reduzir a assimetria de informação, pode haver redução no custo de capital da empresa pelo aumento da demanda de grandes investidores, devido ao aumento de liquidez de seus papéis.

Francis, Khurana e Pereira (2005) salientam que empresas dependentes de financiamento externo são mais suscetíveis de desenvolver maior nível de divulgação de informação, e que maior nível de disclosure, por sua vez, deverá levar a um menor custo de financiamento externo.

No Brasil, em 2000, a BM\&F BOVESPA criou o Nível 1, o Nível 2 e o Novo Mercado, denominados de Níveis Diferenciados de Governança Corporativa, ou NDGC. O objetivo geral era proporcionar um ambiente de negociação que estimulasse, ao mesmo tempo, o interesse dos investidores e a valorização das companhias, sendo esses níveis fundamentados nos quatro princípios básicos de uma boa governança já expostos.

Cada nível possui exigências que podem ser consideradas como boas práticas de governança corporativa. O Nível 1, por exemplo, apresenta o menor número de regras, sendo que poucas são as diferenças encontradas em relação à Lei das Sociedades por Ações (Lei $n^{\circ}$ 6.404/76). Entre estas, podemos citar: circulação mínima de $25 \%$ das ações, divulgação de demonstrações financeiras trimestrais, não ter partes beneficiárias, etc. O Nível 2, por sua vez, tem as mesmas regras estabelecidas no Nível 1 mais outras, como: o mandato do Conselho de Administração é de no máximo 2 anos, sendo permitida a reeleição; é preciso haver, no mínimo, $20 \%$ de membros independentes; demonstrações em padrões internacionais; tag along de $80 \%$; entre outras. Por fim, o Novo Mercado abrange as regras exigidas pelo Nível 2, emissão apenas de ações do tipo ordinárias e tag along de $100 \%$.

Segundo a BM\&F BOVESPA, as empresas que adotam as exigências desses níveis terão alguns benefícios, dentre os quais, podem ser citados: a) Para os investidores: maior precisão na precificação das ações, maior segurança quanto aos seus direitos societários, redução do risco; b) Para as empresas: maior demanda por suas ações, menor custo de capital; c) Para o mercado acionário: aumento de liquidez; entre outros. Para ilustrar, pode-se dizer que ao mesmo tempo em que a adoção às práticas diferenciadas de governança corporativa faz aumentar a demanda pelas ações da empresa, ela também faz com que os investidores ocorram em menor risco, tornando o mercado acionário uma melhor alternativa de investimento. Isso, por sua vez, afeta a economia nacional, com uma maior canalização da poupança da população nas empresas.

Schadewitz e Blevins (1998) mencionam que, quando os investidores são racionais, acabam percebendo os possíveis riscos das empresas e, assim, evitam assumir posições acionárias em companhias nas quais a quantidade e a qualidade da evidenciação de informação é consideravelmente baixa em relação as suas expectativas.

Segundo Lanzana (2004), quando uma empresa se compromete em fornecer informações de alta qualidade para o mercado, tem como consequência a redução na assimetria informacional entre os investidores, o que reduz a seleção adversa e o risco de liquidez e atrai mais fundos para o mercado de capitais. 
Dessa forma, se as boas práticas de governança da BM\&F BOVESPA buscam, entre outras coisas, maior transparência das informações prestadas aos usuários e tomadores de decisões, é possível pensar que estes terão melhor embasamento e segurança ao decidir investir em empresas que adotam tais práticas.

\subsection{Risco}

No que se refere à previsão de dado acontecimento ou comportamento, é possível ter mais ou menos incerteza sobre o que ocorrerá. Quando se pode mensurar a incerteza, essa medida é denominada risco.

Ao se fazer o levantamento histórico dos retornos de um título e calcular o retorno médio, é possível utilizar essa medida como o retorno esperado daquele título para um período futuro. Porém, deve-se ressaltar que se trata, antes de qualquer coisa, de uma expectativa. 0 retorno futuro pode, naturalmente, variar em relação ao retorno médio calculado com base em dados históricos.

Em finanças, uma medida utilizada como representativa do risco é o desvio-padrão dos retornos dos títulos, sob a assunção de uma distribuição normal desses retornos.

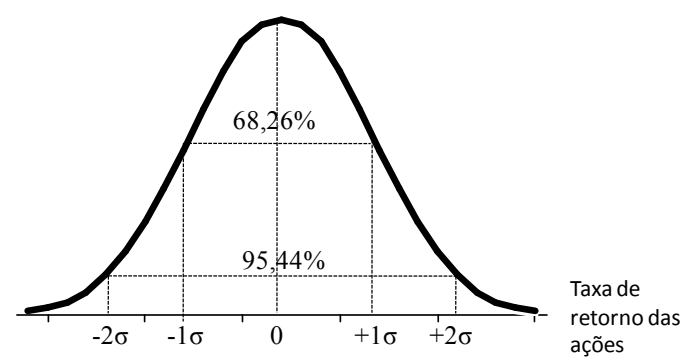

Figura 1: Desvio-padrão de um ativo segundo a distribuição normal

Risco refere-se à variação como um todo, para mais ou para menos, ou seja, a probabilidade de um retorno ocorrer acima ou abaixo de sua média esperada. Isso significa que risco está relacionado com a noção sobre quanto o retorno de um ativo pode variar. Ross, Westerfield e Jaffe (1995, p. 198) afirmam ainda que o retorno esperado de um título está positivamente relacionado ao seu risco, pois os investidores somente assumirão riscos adicionais se receberem compensação adicional.

Muitos estudos sobre risco tiveram como ponto base o trabalho de Markowitz (1952). Segundo o autor, uma carteira é um conjunto de ativos financeiros cujo retorno é formado pela soma dos retornos de cada ativo ponderada pela participação de seu valor no portfólio. O risco da carteira, entretanto, não é obtido apenas como uma média ponderada dos riscos de cada ativo; há que se considerar os efeitos de covariâncias, ou correlações, entre as variações de preços dos ativos. Esse risco tem um componente sistemático e outro não sistemático, sendo este possível de ser eliminado por meio da diversificação.

Ross, Westerfield e Jaffe (1995) afirmam que o desvio-padrão de uma ação isolada não é boa medida de como o desvio-padrão do retorno da carteira se altera quando uma ação lhe é acrescentada, logo o desvio-padrão do retorno de um título não é boa medida de seu risco quando todos os investidores detêm carteiras diversificadas. 
Os autores afirmam que o risco de um título individual é bem representado pelo seu coeficiente beta $\beta$, o qual informa a tendência de uma ação individual ao variar em conjunto com o mercado, ou seja, é uma maneira de verificar a sensibilidade de um título em relação ao mercado. Portanto, o $\beta$ é usado como uma medida de risco sistemático. Assim, de acordo com Ross, Westerfield e Jaffe (1995, p.183), o retorno esperado de um título pode ser uma função direta de seu beta. Com a adesão das empresas aos níveis de governança corporativa, elas sinalizam ao mercado que estão dispostas a diminuir a assimetria de informações entre os participantes do mercado de capitais e transmitir maior segurança aos investidores. Portanto, se o objetivo dos NDGC é, entre outros, melhor qualidade da informação prestada, de forma que esta seja relevante e confiável, o investidor é capaz de verificar, de modo mais seguro, como está o desempenho e a situação financeira das companhias. Desse modo, o investidor pode aplicar seus recursos com base no melhor aporte informacional, o que significa menor risco nas decisões, o que poderia acarretar em uma redução do beta da empresa.

\subsection{Pesquisas Nacionais e Internacionais}

Pesquisas nacionais e internacionais buscam explicar ou verificar a relação da qualidade da evidenciação e boas práticas de governança corporativa com o custo de capital próprio das empresas.

Carvalho (2002) fez um estudo para a BM\&F BOVESPA sobre os efeitos da migração das empresas paras os NDGC, considerando três aspectos: preço, volume e volatilidade e liquidez das ações. Constatou, entre outras coisas, que ocorreu um aumento de liquidez das ações das empresas estudadas após a migração para os níveis de governança.

Camargos e Barbosa (2006) analisaram a influência da adesão aos NDGC sobre o comportamento das ações, por meio de estudos de eventos, com o intuito de identificar se ocorreram mudanças significativas sobre o Retorno Anormal Acumulado (RAA) e sobre a liquidez. A liquidez foi medida por meio de três variáveis: quantidade de negociações, quantidade de títulos e volume financeiro. O estudo considerou o período de 1992 a 2002, sendo a amostra constituída de 34 empresas, as quais estavam listadas nos NDGC. Os pesquisadores constataram que o retorno acionário anormal não foi maior após a data de adesão, porém a liquidez apresentou aumento significativo após a adesão.

Macedo, Mello e Tavares Filho (2006), por meio de um estudo empírico analítico, procuraram verificar se houve variações significativas no risco das ações das empresas que aderiram ao Nível 1 de governança da BM\&F BOVESPA. Para isso, eles analisaram dois anos antes e dois após a adesão das empresas, por meio do teste-t e do teste de Wilcoxon, para duas amostras emparelhadas. Contudo, não conseguiram verificar estatisticamente que a adesão a esse nível altera a percepção de risco de tais empresas.

Nakamura et al (2006) tiveram como objetivo a associação existente entre disclosure e custo de capital próprio das companhias abertas brasileiras. Para isso, utilizaram o Método dos Mínimos Quadrados Ordinários, o modelo do CAPM, de Dividendos Descontados e de Ohlson, para cálculo do custo de capital próprio. Os testes foram efetuados sobre duas amostras não probabilísticas compostas por empresas com ações negociadas na BM\&F BOVESPA. Como resultado, verificaram que o modelo escolhido para cálculo do custo de capital interfere nos resultados obtidos nos testes empíricos, e que a variável disclosure pode se apresentar significativa em um modelo e não significativa em outro.

Martins, Silva e Nardi (2006) procuraram verificar se as empresas que aderiram aos 
NDGC tiveram redução no seu custo de captação. Considerando que essa medida seria difícil de observar, utilizaram o comportamento da liquidez das ações. $O$ estudo baseou-se em análises gráficas, regressão simples e comparação emparelhada de média e variância. Os resultados obtidos demonstraram que há alteração no nível de liquidez, notadamente para as ações ON que apresentaram nível de significância satisfatório, e que há fortes indícios de que a migração das empresas do mercado tradicional para um dos NDGC tem impacto na liquidez de suas ações e, consequentemente, de maneira indireta, no custo de capital dessas empresas.

Kitagawa et al (2007) partiram do objetivo de verificar o comportamento do custo de capital próprio das empresas que aderiram ao Nível 1 e 2 de governança corporativa da BM\&F BOVESPA, sendo que, devido ao fato de as empresas aderirem aos NDGC em datas diferentes, trabalharam com dados a partir de 1998 até 2005. Para isso, os autores utilizaram custo de capital próprio calculado com base na metodologia proposta por Assaf Neto (2003), o qual é fundamentado no conceito de benchmark, e analisaram a série histórica de seu comportamento antes e após a adesão das empresas. Como resultado, constataram que o Nível 2 apresenta menor custo de capital que o Nível 1.

Além desses estudos, pode-se citar Rabelo et al (2007). Os autores buscaram averiguar se as empresas que adotam práticas de governança apresentam melhor desempenho do que aquelas que não adotam tais práticas, utilizando um estudo de carteiras com três estratégias de diversificação diferentes. Por meio do método de reamostragem bootstrap, comparou-se as médias das carteiras em relação ao retorno, risco e retorno ajustado ao risco, no período de janeiro de 2003 a outubro de 2006. No cálculo dos retornos, foram utilizadas as taxas reais mensais e, em relação às medidas de risco dos retornos reais mensais, o desvio-padrão, o coeficiente de variação, a semivariância e o coeficiente beta. Relativamente aos retornos ajustados ao risco, usaram-se os seguintes indicadores: Índice de Sharpe (IS), Índice de Treynor (T), Índice $\mathrm{M}^{2}$, Alfa de Jensen $(\alpha)$ e Índice de Sortino (S). Estatisticamente os resultados não mostram diferenças nas carteiras formadas pelos dois tipos de empresas.

Considerando-se os estudos em âmbito internacional, Botosan (1997) examinou a associação entre o nível de disclosure e o custo de capital próprio, por meio de análise de regressão entre o custo de capital próprio e uma medida do nível de disclosure desenvolvida pela autora. Tal medida é baseada na evidenciação voluntária, no relatório anual de 1990, de uma amostra de 120 empresas de produção. A autora verificou que, quando as empresas apresentam baixo nível de analistas desempenhando papel significativo no processo de comunicação, uma maior divulgação está associada a um menor custo de capital, dado que a mudança de uma unidade na medida de disclosure está associada com uma mudança de vinte oito pontos bases no custo de capital próprio. Mas, para empresas com alto nível de analistas desempenhando papel significativo no processo de comunicação, não foi possível observar qualquer evidência.

Healy, Hutton e Palepu (1999) investigaram se o disclosure voluntário estava associado com alguns fatores do mercado, como retorno das ações, estrutura de propriedade, acompanhamento no processo de comunicação pelos analistas, liquidez das ações, entre outros. A amostra foi selecionada com base em empresas com melhorias na qualidade da evidenciação, com base no rating de qualidade de disclosure reportado na Association of Investment Management and Research Corporate Information Commitee Reports (AIMR). Por meio de estatística descritiva, medidas de posição e regressão múltipla verificaram um aumento no disclosure, seguido de aumento em todas as outras variáveis consideradas.

Gode e Mohanram (2001), por sua vez, encontraram uma associação fortemente positiva entre o custo de capital próprio, com a variabilidade dos resultados e a volatilidade sistemática 
e não sistemática do retorno, e uma associação negativa com acompanhamento no processo de comunicação pelos analistas. Os autores utilizaram modelo de Ohlson e Juettner para cálculo do custo de capital, o período analisado foi de 1984 a 1998, e utilizaram estatística descritiva, análise gráfica e regressão múltipla, com dados dispostos em painel.

Botosan e Plumblee (2002), por meio do modelo de desconto de dividendos, calcularam o custo de capital próprio para, então, relacionar com o disclosure das empresas. Utilizaram empresas incluídas na AIMR de 1985/86 a 1995/96 e analisaram por meio de estatística descritiva, análise univariada e análise multivariada. Assim, verificaram que o custo de capital próprio diminui com nível de divulgação dos relatórios anuais, mas aumenta no momento da evidenciação.

Hail (2002) tenta quantificar o efeito da política de disclosure sobre o custo de capital próprio das empresas Suíças, por meio de análise cross-sectional, no ano de 1997. A qualidade do disclosure foi avaliada pelo montante de evidenciação voluntária presente nos relatórios anuais divulgados, e o custo de capital foi medido usando o modelo de lucro residual. Utilizando estatística descritiva, correlação de Pearson e regressão múltipla, o autor encontrou uma relação negativa e altamente significativa entre essas duas variáveis.

Francis, Khurana e Pereira (2005) investigaram a relação de custo de capital e disclosure de empresas de diversos países onde alternativas legais e sistemas financeiros podem atuar na eficácia da divulgação. Usaram uma amostra de 34 países, entre eles, Brasil, França, Portuga, Itália e Israel, nos anos de 1991 a 1993. Como método, empregaram estatística descritiva e regressão múltipla. Assim, concluíram que as empresas com maior necessidade de financiamento externo têm maior divulgação voluntária e que uma política de divulgação conduziu essas empresas a menores custos de captação tanto de capital próprio quanto de terceiros.

Por fim, Lambert, Leuz e Verrecchia (2007), construindo um modelo consistente com o CAPM, procuraram examinar "se" e "como" a informação contábil se manifesta no custo de capital. Dessa maneira, demonstram que a qualidade da informação contábil pode influenciar o custo de capital de forma direta e indireta.

\section{METODOLOGIA}

Esse estudo pode ser classificado, de acordo com Collis e Hussey (2005), como longitudinal, pois observa uma variável de um grupo de sujeitos ao longo do tempo. Os autores afirmam que estes estudos permitem avaliar mudanças em uma conjuntura social, econômico e político. Assim, é possível verificar a estabilidade de um determinado fenômeno a partir de um exame dos processos de mudança e de novos padrões que surgem.

O fenômeno investigado neste artigo tem origem na adesão de algumas empresas de capital aberto brasileiras aos NDGC da BM\&F BOVESPA. Espera-se que, após a migração dessas empresas, haja alguma mudança quanto ao nível de risco, na percepção do investidor e não necessariamente no risco do negócio de tais empresas, o que é afirmado pela BM\&F BOVESPA e verificado por alguns estudos nacionais [(MACEDO, MELLO e TAVARES FILHO, 2006) e (KITAGAWA et al, 2007)]. Portanto, esse acontecimento, associado à expectativa de variação no risco, foi definido como o objeto de estudo.

Para analisar o risco das empresas, utilizou-se como proxy os betas $(\beta)$ e o desviopadrão dos retornos diários. O beta como variável representativa do risco das empresas, apesar de algumas limitações, foi utilizado nos trabalhos de Cardoso (2000), Alencar e Lopes (2005), Macedo, Mello e Tavares Filho (2006), Toledo e Pamplona (2006), Rabelo et al (2007).

Com relação à amostra, partiu-se de todas as empresas dos níveis de governança 
corporativa da BM\&F BOVESPA, o que significa 153 empresas listadas até novembro de 2007 (44 no Nível 1, 20 no Nível 2 e 89 no Novo Mercado). Foram excluídas as empresas que fizeram IPO (Initial Public Offering), por não apresentarem séries históricas de cotações de seus papéis na BM\&F BOVESPA, no período anterior ao da adesão ao segmento especial. Assim, o número de empresas passou para 94, sendo 34 empresas no Nível 1 (N1), 13 no Nível 2 (N2) e 47 empresas no Novo Mercado (NM).

Consequentemente, a amostragem não foi probabilística, pois foi preciso verificar se as empresas apresentavam dados disponíveis. A disponibilidade de dados deveria atender a 252 dias antes e após a data de adesão. Esse intervalo de tempo foi utilizado também por Camargos e Barbosa (2006). Como nem todas as empresas possuem dados de fechamento nesse intervalo de tempo, essa limitação reduziu o número de empresas para 48 (36 do N1, 6 do N2 e 6 do NM), ou seja, cerca de $31 \%$ das empresas totais ou $51 \%$ das empresas que não fizeram IPO.

Foram coletadas as séries históricas de cotações diárias das ações, o preço de fechamento das empresas listadas nos níveis de governança e do lbovespa.

Os retornos das ações das empresas foram calculados através da seguinte equação:

$$
R_{i, t}=\frac{P_{i, t}-P_{i, t-1}}{P_{i, t-1}}
$$

Na qual:

$\mathrm{R}_{\mathrm{i}, \mathrm{t}}$ é o retorno da ação da empresa i no tempo $\mathrm{t}$;

$P_{i, t}$ é o preço da ação da empresa i no tempo t; e

$P_{i, t-1}$ é o preço da ação da empresa i no tempo t-1.

Em seguida, foi feita uma comparação de médias dos retornos antes e após a data de adesão. Para isso, foi realizado um teste paramétrico de médias emparelhadas, respeitando o pressuposto da normalidade. Vale ressaltar que esses testes foram feitos por ação e em conjunto: de acordo com o NDGC (N1, N2 e NM), e abrangendo todas as ações, sem distinção de NDGC.

$O$ beta de cada um dos ativos foi calculado por meio da seguinte equação:

$$
\beta=\frac{\operatorname{Cov}\left(R_{i, t}, R_{M, t}\right)}{\operatorname{Var}\left(R_{M, t}\right)}
$$

Na qual:

$\operatorname{Cov}\left(\mathrm{R}_{\mathrm{i}, \mathrm{t}^{\prime}}, \mathrm{R}_{\mathrm{M}, \mathrm{t}}\right)$ : covariância do ativo i com a carteira de mercado na data t; e $\operatorname{Var}\left(\mathrm{R}_{\mathrm{M}, \mathrm{t}}\right)$ : variância da carteira de mercado.

E o desvio-padrão (DP) foi encontrado seguindo a seguinte formulação:

$$
D P=\sqrt{\frac{\sum\left(R_{i}-\bar{R}\right)^{2}}{(n-1)}}
$$

Na qual:

$\mathrm{R}$ : retorno do ativo i;

$R$ : retorno médio; e

$\mathrm{n}$ : número de observações.

Para o cálculo do beta e do desvio-padrão, foram usados 60 retornos diários a partir do $252^{\circ}$ dia anterior à data de adesão, com o deslocando de um dia até a data de migração, como pode ser visto, a título de ilustração, na figura 2 . Essa maneira de cálculo reduziu a quantidade de observações de 252 dias para 192, ou seja, a janela reduziu em 60 dias. 
Figura 2: Forma de organização dos dados para cálculo do beta e do desvio-padrão

Fonte: elaborada pelos autores.

Após os cálculos das proxies, foi feito um teste de normalidade (teste KolmogorovSmirnov). Para aquelas que apresentaram uma distribuição normal, foi aplicado o teste paramétrico de médias emparelhadas. Em adicional, foi empregado um teste não paramétrico (Wilcoxon) para que todos os ativos pudessem ser analisados.

\section{Aplicação dos Testes e Análise dos Resultados}

De acordo com Triola (1998), deve-se verificar a normalidade das diferenças de cada par de observações antes de aplicar o teste paramétrico de médias emparelhadas. Assim, utilizou-se o teste não paramétrico Kolmogorov-Smirnov (KS) para verificar se as diferenças dos retornos apresentam uma distribuição normal, como pode ser observado no Quadro 1. É importante destacar as hipóteses do teste: a hipótese nula $\mathrm{H}_{0}$ afirma que a amostra vem de uma distribuição normal $N(\mu, \sigma)$; a hipótese alternativa $H_{1}$ afirma que a amostra não vem de uma distribuição normal $N(\mu, \sigma)$ (FÁVERO et al; 2009, p. 113).

Quadro 1: Teste KS e Levene para os retornos por empresa

\begin{tabular}{|c|c|c|c|c|c|c|c|}
\hline & Empresa & $\begin{array}{c}\text { Prob }\left(\mathrm{D}>\mathrm{D}_{\mathrm{o}}\right) \\
\text { do } \mathrm{KS}\end{array}$ & $\begin{array}{l}\text { Sig. de Le- } \\
\text { vene }\end{array}$ & & Empresa & $\begin{array}{c}\text { Prob (D>Do) } \\
\text { do KS }\end{array}$ & $\begin{array}{l}\text { Sig. De Le- } \\
\text { vene }\end{array}$ \\
\hline \multirow{11}{*}{ 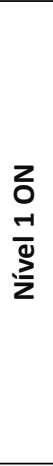 } & BRADESCO & 0,948 & 0,015 & \multirow{12}{*}{$\begin{array}{l}z \\
a \\
-1 \\
\bar{d} \\
\frac{z}{z}\end{array}$} & GERDAU & 0,765 & 0,521 \\
\hline & ITAUBANCO & 0,061 & 0,001 & & IOCHP-MAXION & 0,106 & 0,002 \\
\hline & BRADESPAR & 0,322 & 0,595 & & ITAUSA & 0,688 & 0,194 \\
\hline & BRASIL T PAR & 0,234 & 0,000 & & KLABIN S/A & 0,778 & 0,000 \\
\hline & BRASIL TELEC & 0,471 & 0,001 & & GERDAU MET & 0,11 & 0,001 \\
\hline & ELETROBRAS & 0,937 & 0,001 & & RANDON PART & 0,613 & 0,000 \\
\hline & CESP & 0,355 & 0,008 & & SADIA S/A & 0,41 & 0,000 \\
\hline & CEMIG & 0,508 & 0,658 & & SUZANO PAPEL & 0,944 & 0,659 \\
\hline & TRAN PAULIST & 0,462 & 0,634 & & ULTRAPAR & 0,943 & 0,205 \\
\hline & VALE R DOCE & 0,953 & 0,002 & & UNIBANCO & 0,124 & 0,986 \\
\hline & UNIBANCO & 0,000 & 0,628 & & UNIPAR & 0,774 & 0,739 \\
\hline \multirow{13}{*}{$\begin{array}{l}z \\
a \\
-1 \\
\frac{\partial}{2} \\
\frac{2}{z}\end{array}$} & ARACRUZ & 0,686 & 0,109 & & VCP & 0,99 & 0,144 \\
\hline & ITAUBANCO & 0,848 & 0,003 & \multirow{6}{*}{$\begin{array}{l}z \\
\frac{z}{2} \\
\frac{N}{2} \\
\frac{2}{z}\end{array}$} & CELESC & 0,055 & 0,009 \\
\hline & BRADESPAR & 0,646 & 0,000 & & ELETROPAULO & 0,785 & 0,085 \\
\hline & BRASIL T PAR & 0,999 & 0,002 & & MARCOPOLO & 0,235 & 0,138 \\
\hline & BRASIL TELEC & 0,849 & 0,018 & & NET & 0,382 & 0,616 \\
\hline & BRASKEM & 0,413 & 0,404 & & SARAIVA LIVR & 0,065 & 0,071 \\
\hline & ELETROBRAS & 0,967 & 0,000 & & SUZANO PETR & 0,212 & 0,248 \\
\hline & CESP & 0,736 & 0,013 & \multirow{6}{*}{ 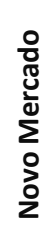 } & BRASIL & 0,129 & 0,000 \\
\hline & CEMIG & 0,774 & 0,402 & & SABESP & 0,533 & 0,827 \\
\hline & TRAN PAULIST & 0,956 & 0,000 & & EMBRAER & 0,949 & 0,000 \\
\hline & VALE R DOCE & 0,861 & 0,002 & & ETERNIT & 0,025 & 0,000 \\
\hline & CONFAB & 0,541 & 0,006 & & LIGHT S/A & 0,638 & 0,053 \\
\hline & DURATEX & 0,815 & 0,000 & & TRACTEBEL & 0,772 & 0,000 \\
\hline
\end{tabular}

Fonte: elaborado pelos autores.

Por meio dos dados do quadro anterior, pode-se verificar que a maioria das diferenças dos retornos atendeu o pressuposto de normalidade. Apenas duas empresas, Unibanco e Eternit, não atendem o pressuposto da normalidade, já que $p$-value é inferior a 5\%, o que leva a rejeitar a hipótese nula de normalidade. Sendo assim, tais empresas foram excluídas do teste de médias 
emparelhadas.

Além da premissa de normalidade nos dados, o teste t de Student para comparação de duas médias populacionais a partir de duas amostras aleatórias relacionadas (ou simplesmente teste de médias emparelhadas) exige que as variâncias de cada amostra sejam iguais entre si (Fávero et al 2009, p. 128). Para avaliar a variância dos dados, aplicou-se o teste de Levene, sendo que as hipóteses do teste são as seguintes: a hipótese nula estabelece que as variâncias populacionais sejam homogêneas, ou seja, $\mathrm{H}_{0}: \sigma_{1}^{2}=\sigma_{2}^{2}$; por outro lado, a hipótese alternativa define que as variâncias populacionais sejam diferentes ou $\mathrm{H}_{1}: \sigma_{1}^{2} \neq \sigma_{2}^{2}$.

Pelo quadro 1, pode-se observar que 27 empresas apresentaram Sig. de Levene ou $p$-value inferior a $5 \%$, o que permite rejeitar a hipótese nula e concluir que não há homogeneidade nas variâncias. Logo, para essas empresas, não é possível aplicar o teste t de Student.

Foi aplicado o teste $t$ de Student, para amostras emparelhadas ou relacionadas, apenas para os casos em que não foi possível rejeitar a hipótese nula tanto no teste KS quanto no teste de Levene, isto é, nos quais se observou normalidade e variâncias homogêneas, cujos resultados estão resumidos no quadro 2. Vale destacar que, de acordo com Fávero et al (2009, p. 129), as hipóteses do teste $t$ são: a hipótese nula estabelece que as médias populacionais são iguais, ou seja, $H_{0}: \mu_{x}=\mu_{y^{\prime}}$ a hipótese alternativa considera que as médias são diferentes, $H_{1}: \mu_{x} \neq \mu_{y}$.

Quadro 2 - Teste de Médias Emparelhadas para retorno

\begin{tabular}{|c|c|c|c|c|c|c|c|c|c|}
\hline & Empresa & DMédia & "t" & DF & & Empresa & DMédia & "t" & DF \\
\hline \multirow{3}{*}{$\begin{array}{l}\text { N1 } \\
\text { ON }\end{array}$} & BRADESPAR & 0,00004 & 0,014 & 213 & \multirow{3}{*}{$\begin{array}{l}\text { N1 } \\
\text { PN }\end{array}$} & UNIBANCO & 0,00138 & 0,628 & 250 \\
\hline & CEMIG & 0,00111 & 0,390 & 250 & & UNIPAR & 0,00431 & $2,033^{* *}$ & 250 \\
\hline & TRAN PAULIST & $-0,00455$ & $-1,985^{* *}$ & 250 & & VCP & $-0,00004$ & $-0,017$ & 250 \\
\hline \multirow{7}{*}{$\begin{array}{l}\text { N1 } \\
\text { PN }\end{array}$} & ARACRUZ & 0,00214 & 0,963 & 250 & \multirow{5}{*}{$\begin{array}{l}\text { N2 } \\
\text { PN }\end{array}$} & ELETROPAULO & $-0,00101$ & $-0,333$ & 250 \\
\hline & BRASKEM & 0,00391 & 1,447 & 250 & & MARCOPOLO & 0,00094 & 0,577 & 250 \\
\hline & CEMIG & $-0,00021$ & $-0,086$ & 250 & & NET & 0,00089 & 0,170 & 250 \\
\hline & GERDAU & $-0,00288$ & $-1,072$ & 250 & & SARAIVA LIVR & 0,00313 & 1,557 & 250 \\
\hline & ITAUSA & 0,00116 & 0,612 & 250 & & SUZANO PETR & 0,00630 & $2,651 * *$ & 250 \\
\hline & SUZANO PAPEL & 0,00306 & 1,555 & 250 & \multirow{2}{*}{ NM } & SABESP & 0,00095 & 0,376 & 250 \\
\hline & ULTRAPAR & $-0,00093$ & $-0,513$ & 250 & & LIGHT S/A & $-0,00306$ & $-1,003$ & 250 \\
\hline
\end{tabular}

** Significante em nível de 5\%. Fonte: elaborado pelos autores.

Ao observar o quadro anterior, nota-se que as empresas Tran Paulist, Unipar e Suzano Petroquímica foram as únicas que apresentaram uma estatística t significante estatisticamente, no nível de 5\%, o que permite rejeitar formalmente a hipótese nula de médias iguais e concluir que, para essas empresas, o retorno é diferente após o período de adesão aos Níveis de Governança Corporativa. O resultado para as demais pode indicar que a adesão destas aos Níveis de Governança não causou mudanças nas expectativas dos agentes de mercado, dado que o resultado não apresentou alterações significativas nos retornos dos títulos.

Esses resultados corroboram os trabalhos de Aguiar, Corrar e Batistella (2004) que analisaram os impactos da adesão ao Nível 1 de governança corporativa no volume, na quantidade e no preço das ações da empresa, por meio de teste não paramétrico de Wilcoxon. Esses autores verificaram que não houve mudanças positivas e significativas com a migração das empresas para o nível 1, assim como os trabalhos de Batistella et al (2004); Camargos e Barbosa (2006); Macedo, Mello e Tavares Filho (2006); Pedreira e Santos (2006); Rabelo et al (2007). Por outro lado, difere dos resultados encontrados por Malacrida e Yamamoto (2006); Sirqueira, Kalatzis, Toledo (2007).

Após análise dos retornos, os mesmos passos foram aplicados para o desvio e o beta 
das empresas. Os mesmos testes de normalidade e variância foram feitos para o desvio-padrão, os quais podem ser observados a seguir.

Quadro 3: Teste KS e Levene aplicado aos desvios por empresa

\begin{tabular}{|c|c|c|c|c|c|c|c|}
\hline & Empresa & $\begin{array}{c}\text { Prob }\left(D>D_{0}\right) \\
\text { do KS }\end{array}$ & $\begin{array}{l}\text { Sig. de Le- } \\
\text { vene }\end{array}$ & & Empresa & $\begin{array}{c}\text { Prob }\left(D>D_{0}\right) \\
\text { do KS }\end{array}$ & $\begin{array}{l}\text { Sig. de } \\
\text { Levene }\end{array}$ \\
\hline \multirow{11}{*}{ 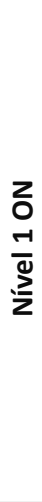 } & BRADESCO & 0,211 & 0,000 & \multirow{12}{*}{$\begin{array}{l}z \\
a \\
\frac{1}{0} \\
\frac{2}{z}\end{array}$} & GERDAU & 0,077 & 0,001 \\
\hline & ITAUBANCO & 0,000 & 0,000 & & IOCHP-MAXION & 0,000 & 0,001 \\
\hline & BRADESPAR & 0,015 & 0,000 & & ITAUSA & 0,002 & 0,391 \\
\hline & BRASIL T PAR & 0,079 & 0,124 & & KLABIN S/A & 0,030 & 0,000 \\
\hline & BRASIL TELEC & 0,000 & 0,000 & & GERDAU MET & 0,243 & 0,000 \\
\hline & ELETROBRAS & 0,001 & 0,000 & & RANDON PART & 0,000 & 0,419 \\
\hline & CESP & 0,043 & 0,000 & & SADIA S/A & 0,000 & 0,000 \\
\hline & CEMIG & 0,000 & 0,000 & & SUZANO PAPEL & 0,051 & 0,000 \\
\hline & TRAN PAULIST & 0,035 & 0,000 & & ULTRAPAR & 0,051 & 0,000 \\
\hline & VALE R DOCE & 0,410 & 0,000 & & UNIBANCO & 0,005 & 0,000 \\
\hline & UNIBANCO & 0,000 & 0,000 & & UNIPAR & 0,104 & 0,398 \\
\hline \multirow{13}{*}{$\begin{array}{l}z \\
\frac{z}{a} \\
\frac{1}{\alpha} \\
\frac{2}{z}\end{array}$} & ARACRUZ & 0,112 & 0,000 & & VCP & 0,002 & 0,000 \\
\hline & ITAUBANCO & 0,012 & 0,000 & \multirow{6}{*}{$\begin{array}{l}z \\
\mathbf{z} \\
\mathbf{N} \\
\overline{0} \\
\frac{2}{2}\end{array}$} & CELESC & 0,000 & 0,000 \\
\hline & BRADESPAR & 0,000 & 0,000 & & ELETROPAULO & 0,000 & 0,000 \\
\hline & BRASIL T PAR & 0,034 & 0,000 & & MARCOPOLO & 0,006 & 0,000 \\
\hline & BRASIL TELEC & 0,009 & 0,190 & & NET & 0,000 & 0,000 \\
\hline & BRASKEM & 0,000 & 0,000 & & SARAIVA LIVR & 0,207 & 0,000 \\
\hline & ELETROBRAS & 0,000 & 0,000 & & SUZANO PETR & 0,089 & 0,000 \\
\hline & CESP & 0,004 & 0,000 & \multirow{6}{*}{$\begin{array}{l}\text { 유 } \\
\text { ల } \\
\frac{0}{0} \\
\sum^{2} \\
0 \\
0 \\
2\end{array}$} & BRASIL & 0,000 & 0,000 \\
\hline & CEMIG & 0,001 & 0,000 & & SABESP & 0,004 & 0,000 \\
\hline & TRAN PAULIST & 0,245 & 0,000 & & EMBRAER & 0,000 & 0,583 \\
\hline & VALE R DOCE & 0,000 & 0,001 & & ETERNIT & 0,000 & 0,804 \\
\hline & CONFAB & 0,196 & 0,000 & & LIGHT S/A & 0,060 & 0,851 \\
\hline & DURATEX & 0,008 & 0,170 & & TRACTEBEL & 0,000 & 0,000 \\
\hline
\end{tabular}

Fonte: elaborado pelos autores.

Os dados do quadro 3 revelam que a maioria (71\% das ações) das diferenças dos desvios não está de acordo com o pressuposto da normalidade. Em relação ao pressuposto de variâncias homogêneas, $81 \%$ das ações não atendem a tal premissa, não permitindo aplicar o teste $t$ de Student para grande parte das empresas. Apenas Brasil T Par, Unipar e Light S/A atenderam aos dois pressupostos impostos pelo teste de médias emparelhadas. Os resultados encontram-se a no quadro seguir.

Quadro 4: Teste de diferença de médias emparelhadas para os desvios

\begin{tabular}{|c|c|c|c|c|}
\hline & Empresa & DMédia & "t" & DF \\
\hline N1 ON & BRASIL T PAR & 0,00802 & $10,432^{* *}$ & 191 \\
\hline N1 PN & UNIPAR & 0,00330 & $16,495^{* *}$ & 191 \\
\hline NM & LIGHT S/A & 0,00513 & $4,936^{* *}$ & 191 \\
\hline
\end{tabular}

** Significante em nível de 5\%. Fonte: elaborado pelos autores.

A estatística t gerada pelo teste é significante estatisticamente em nível de $5 \%$. Sendo assim, rejeita-se a hipótese nula de médias iguais e conclui-se que o desvio-padrão - uma proxy para risco - para as três companhias, sofreu uma mudança relevante após a data de adesão. Deve-se ressaltar que não foi verificado se o risco aumentou ou diminuiu, pois não era objetivo 
da pesquisa. Com relação às outras 45 empresas, não se pode afirmar sobre o desvio, já que os pressupostos básicos do teste de médias emparelhadas, normalidade e variâncias homogêneas, não foram atendidos.

A seguir, encontram-se os resultados dos testes KS e Levene para os betas das 48 ações.

Quadro 5: Teste KS e Levene aplicado aos betas por empresa

\begin{tabular}{|c|c|c|c|c|c|c|c|}
\hline & Empresa & $\begin{array}{c}\text { Prob }\left(D>D_{0}\right) \\
\text { do KS }\end{array}$ & $\begin{array}{l}\text { Sig. de } \\
\text { Levene }\end{array}$ & & Empresa & $\begin{array}{c}\text { Prob }\left(D>D_{0}\right) \\
\text { do KS }\end{array}$ & $\begin{array}{l}\text { Sig. de } \\
\text { Levene }\end{array}$ \\
\hline \multirow{11}{*}{ 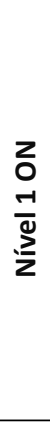 } & BRADESCO & 0,014 & 0,000 & \multirow{12}{*}{$\begin{array}{l}z \\
a \\
-1 \\
\bar{d} \\
\frac{a}{z}\end{array}$} & GERDAU & 0,816 & 0,012 \\
\hline & ITAUBANCO & 0,001 & 0,001 & & IOCHP-MAXION & 0,001 & 0,000 \\
\hline & BRADESPAR & 0,000 & 0,530 & & ITAUSA & 0,003 & 0,000 \\
\hline & BRASIL T PAR & 0,024 & 0,109 & & KLABIN S/A & 0,138 & 0,000 \\
\hline & BRASIL TELEC & 0,000 & 0,000 & & GERDAU MET & 0,001 & 0,000 \\
\hline & ELETROBRAS & 0,002 & 0,018 & & RANDON PART & 0,003 & 0,000 \\
\hline & CESP & 0,159 & 0,215 & & SADIA S/A & 0,114 & 0,000 \\
\hline & CEMIG & 0,374 & 0,000 & & SUZANO PAPEL & 0,000 & 0,000 \\
\hline & TRAN PAULIST & 0,003 & 0,406 & & ULTRAPAR & 0,187 & 0,000 \\
\hline & VALE R DOCE & 0,020 & 0,000 & & UNIBANCO & 0,022 & 0,000 \\
\hline & UNIBANCO & 0,038 & 0,002 & & UNIPAR & 0,006 & 0,000 \\
\hline \multirow{13}{*}{$\begin{array}{l}z \\
z \\
-1 \\
\bar{d} \\
\frac{z}{z}\end{array}$} & ARACRUZ & 0,000 & 0,000 & & VCP & 0,424 & 0,000 \\
\hline & ITAUBANCO & 0,126 & 0,000 & \multirow{6}{*}{ 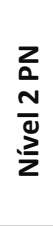 } & CELESC & 0,559 & 0,109 \\
\hline & BRADESPAR & 0,000 & 0,000 & & ELETROPAULO & 0,232 & 0,000 \\
\hline & BRASIL T PAR & 0,009 & 0,000 & & MARCOPOLO & 0,991 & 0,104 \\
\hline & BRASIL TELEC & 0,097 & 0,950 & & NET & 0,007 & 0,000 \\
\hline & BRASKEM & 0,398 & 0,995 & & SARAIVA LIVR & 0,001 & 0,000 \\
\hline & ELETROBRAS & 0,000 & 0,000 & & SUZANO PETR & 0,323 & 0,000 \\
\hline & CESP & 0,000 & 0,000 & \multirow{6}{*}{$\begin{array}{l}\frac{0}{0} \\
\frac{\pi}{2} \\
\frac{1}{0} \\
\sum \\
0 \\
0 \\
\mathbf{z}\end{array}$} & BRASIL & 0,000 & 0,000 \\
\hline & CEMIG & 0,733 & 0,124 & & SABESP & 0,160 & 0,000 \\
\hline & TRAN PAULIST & 0,248 & 0,000 & & EMBRAER & 0,046 & 0,001 \\
\hline & VALE R DOCE & 0,049 & 0,000 & & ETERNIT & 0,009 & 0,008 \\
\hline & CONFAB & 0,003 & 0,000 & & LIGHT S/A & 0,049 & 0,000 \\
\hline & DURATEX & 0,207 & 0,000 & & TRACTEBEL & 0,000 & 0,000 \\
\hline
\end{tabular}

Fonte: elaborado pelos autores.

De acordo com o quadro 5, apenas 6 empresas apresentaram normalidade e variâncias homogêneas: Cesp, Brasil Telec, Braskem, Cemig (Nível 1 PN), Celesc e Marcopolo, para as quais foi feito o teste de diferença de médias ilustrado a seguir.

Quadro 6: Teste de diferença de médias emparelhadas para os betas

\begin{tabular}{|c|c|c|c|c|}
\hline & Empresa & DMédia & "t" & DF \\
\hline \multirow{2}{*}{ N1 ON } & CESP & 0,35369 & $19,832^{* *}$ & 191 \\
\cline { 2 - 5 } & BRASIL TELEC & 0,13727 & $13,702^{* *}$ & 191 \\
\hline \multirow{2}{*}{ N1 PN } & BRASKEM & $-0,20042$ & $-10,945^{* *}$ & 191 \\
\cline { 2 - 5 } & CEMIG & $-0,05937$ & $-4,575^{* *}$ & 191 \\
\hline \multirow{2}{*}{ N2 PN } & CELESC & 0,29583 & $16,711^{* *}$ & 191 \\
\cline { 2 - 5 } & MARCOPOLO & 0,08288 & $10,040^{* *}$ & 191 \\
\hline
\end{tabular}

** Significante em nível de 5\%. Fonte: elaborado pelos autores.

O valor $t$ do teste é significante estatisticamente em nível de $5 \%$, para todos os casos, o que leva a rejeição da hipótese nula, concluindo-se que as médias são diferentes, isto é, o beta das empresas sofreu alteração após a data de adesão aos Níveis de Governança - provavelmente devido a mudanças nas expectativas dos agentes do mercado. Novamente a mesma consideração 
sobre o sentido da variação deve ser lembrada. Ressalta-se que nada se pode afirmar em relação às demais empresas não analisadas neste teste.

Vale observar que, em função de se ter poucas empresas que respeitaram o pressuposto da normalidade, para o desvio e para o beta, foi feito um ajuste no cálculo do retorno das ações, utilizando-se as séries logarítmicas, como também empregado por Batistella et al (2004) e Macedo, Mello e Tavares Filho (2006), da seguinte maneira:

Em que:

$$
R_{t}=\operatorname{Ln}\left(\frac{C_{t}}{C_{t-1}}\right)
$$

Rt: retorno no período $t$,

Ct: cotação no período $t$.

Esse tratamento foi feito com o objetivo de suavizar as séries, ou seja, para encontrar uma distribuição de frequência mais simétrica. Porém, os resultados desses ajustes não foram apresentados neste trabalho, pois não apresentaram diferenças significativas em relação aos testes feitos pelos valores não suavizados.

Em virtude de muitas empresas não atenderem aos pressupostos básicos exigidos pelo teste paramétrico de médias, decidiu-se aplicar o teste não paramétrico de postos, com sinal de Wilcoxon para retorno, desvio e beta com o intuito de verificar se houve diferença entre as variáveis analisadas considerando todos os ativos (48 no total). A hipótese nula do teste afirma não haver diferenças entre os grupos, e a hipótese alternativa afirma haver diferenças (FÁVERO et al, 2009, p. 159).

O quadro a seguir apresenta os resultados do teste de Wilcoxon para a variável retorno.

Quadro 7: Teste de Wilcoxon para retorno

\begin{tabular}{|c|c|c|c|c|c|c|c|}
\hline & Empresa & $\mathbf{Z}$ & Prob $\left(Z>Z_{0}\right)$ & & Empresa & $\mathbf{Z}$ & Prob $\left(Z>Z_{0}\right)$ \\
\hline \multirow{11}{*}{$\begin{array}{l}z \\
0 \\
\text { a-1 } \\
\bar{\Phi} \\
\frac{2}{2}\end{array}$} & BRADESCO & $-0,605$ & 0,545 & \multirow{12}{*}{$\begin{array}{l}z \\
z \\
-1 \\
\bar{d} \\
\frac{z}{z}\end{array}$} & GERDAU & $-1,278$ & 0,201 \\
\hline & ITAUBANCO & $-1,210$ & 0,226 & & IOCHP-MAXION & $-1,233$ & 0,217 \\
\hline & BRADESPAR & $-0,042$ & 0,967 & & ITAUSA & $-0,552$ & 0,581 \\
\hline & BRASIL T PAR & $-0,472$ & 0,637 & & KLABIN S/A & $-2,113$ & 0,035 \\
\hline & BRASIL TELEC & $-1,391$ & 0,164 & & GERDAU MET & $-1,454$ & 0,146 \\
\hline & ELETROBRAS & $-0,181$ & 0,857 & & RANDON PART & $-0,346$ & 0,730 \\
\hline & CESP & $-0,354$ & 0,724 & & SADIA S/A & $-0,267$ & 0,790 \\
\hline & CEMIG & $-0,030$ & 0,976 & & SUZANO PAPEL & $-1,284$ & 0,199 \\
\hline & TRAN PAULIST & $-1,765$ & 0,078 & & ULTRAPAR & $-0,617$ & 0,537 \\
\hline & VALE R DOCE & $-0,234$ & 0,815 & & UNIBANCO & $-0,260$ & 0,795 \\
\hline & UNIBANCO & $-2,902$ & 0,004 & & UNIPAR & $-2,052$ & 0,040 \\
\hline \multirow{13}{*}{$\begin{array}{l}z \\
a \\
\frac{z}{2} \\
\bar{d} \\
\frac{2}{z}\end{array}$} & ARACRUZ & $-0,767$ & 0,443 & & VCP & $-0,121$ & 0,904 \\
\hline & ITAUBANCO & $-0,822$ & 0,411 & \multirow{6}{*}{$\begin{array}{l}z \\
z \\
N \\
\frac{N}{d}\end{array}$} & CELESC & $-0,666$ & 0,505 \\
\hline & BRADESPAR & $-0,369$ & 0,712 & & ELETROPAULO & $-0,539$ & 0,590 \\
\hline & BRASIL T PAR & $-0,623$ & 0,534 & & MARCOPOLO & $-0,494$ & 0,622 \\
\hline & BRASIL TELEC & $-0,683$ & 0,495 & & NET & $-0,496$ & 0,620 \\
\hline & BRASKEM & $-1,159$ & 0,246 & & SARAIVA LIVR & $-1,256$ & 0,209 \\
\hline & ELETROBRAS & $-0,320$ & 0,749 & & SUZANO PETR & $-2,187$ & 0,029 \\
\hline & CESP & $-0,252$ & 0,801 & \multirow{6}{*}{ 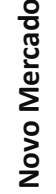 } & BRASIL & $-0,988$ & 0,323 \\
\hline & CEMIG & $-0,079$ & 0,937 & & SABESP & $-0,085$ & 0,932 \\
\hline & TRAN PAULIST & $-0,843$ & 0,399 & & EMBRAER & $-0,190$ & 0,849 \\
\hline & VALE R DOCE & $-0,302$ & 0,762 & & ETERNIT & $-1,235$ & 0,217 \\
\hline & CONFAB & $-0,604$ & 0,546 & & LIGHT S/A & $-1,087$ & 0,277 \\
\hline & DURATEX & $-0,262$ & 0,793 & & TRACTEBEL & $-0,214$ & 0,831 \\
\hline
\end{tabular}

Fonte: elaborado pelos autores.

Ao observar o quadro 7, nota-se que apenas 4 empresas apresentam estatística $Z$ significante estatisticamente em nível de $5 \%$, o que permite rejeitar a hipótese nula de médias iguais. A grande maioria, ou $92 \%$, não apresentou uma mudança na variável retorno após a data de adesão aos níveis, ou seja, o fato da empresa aderir aos níveis de governança não permite 
afirmar que o retorno desta aumentou ou diminuiu. Esse resultado está coerente com Camargos e Barbosa (2006) e Rabelo et al (2007).

Os quadros 8 e 9 apresentam os resultados do teste de Wilcoxon para as variáveis desvio e beta.

Quadro 8: Teste de Wilcoxon para desvio

\begin{tabular}{|c|c|c|c|c|c|c|c|}
\hline & Empresa & Z & $\operatorname{Prob}\left(Z>Z_{0}\right)$ & & Empresa & Z & Prob $\left(Z>Z_{0}\right)$ \\
\hline \multirow{11}{*}{ 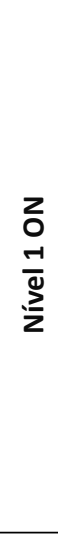 } & BRADESCO & $-5,248$ & 0,000 & \multirow{12}{*}{$\begin{array}{l}z \\
a \\
-1 \\
d \\
\frac{a}{z}\end{array}$} & GERDAU & $-5,528$ & 0,000 \\
\hline & ITAUBANCO & $-2,480$ & 0,013 & & IOCHP-MAXION & $-10,713$ & 0,000 \\
\hline & BRADESPAR & $-9,838$ & 0,000 & & ITAUSA & $-11,431$ & 0,000 \\
\hline & BRASIL T PAR & $-12,016$ & 0,000 & & KLABIN S/A & $-10,320$ & 0,000 \\
\hline & BRASIL TELEC & $-1,630$ & 0,103 & & GERDAU MET & $-11,962$ & 0,000 \\
\hline & ELETROBRAS & $-10,560$ & 0,000 & & RANDON PART & $-9,294$ & 0,000 \\
\hline & CESP & $-11,691$ & 0,000 & & SADIA S/A & $-12,003$ & 0,000 \\
\hline & CEMIG & $-1,812$ & 0,070 & & SUZANO PAPEL & $-0,310$ & 0,757 \\
\hline & TRAN PAULIST & $-9,877$ & 0,000 & & ULTRAPAR & $-1,424$ & 0,154 \\
\hline & VALE R DOCE & $-11,929$ & 0,000 & & UNIBANCO & $-4,361$ & 0,000 \\
\hline & UNIBANCO & $-6,188$ & 0,000 & & UNIPAR & $-1,882$ & 0,060 \\
\hline \multirow{13}{*}{$\begin{array}{l}z \\
a \\
-1 \\
\bar{d} \\
\frac{2}{z}\end{array}$} & ARACRUZ & $-3,348$ & 0,001 & & VCP & $-11,786$ & 0,000 \\
\hline & ITAUBANCO & $-10,505$ & 0,000 & \multirow{6}{*}{$\begin{array}{l}z \\
a \\
N \\
\frac{N}{2} \\
\frac{2}{z}\end{array}$} & CELESC & $-10,866$ & 0,000 \\
\hline & BRADESPAR & $-10,799$ & 0,000 & & ELETROPAULO & $-10,974$ & 0,000 \\
\hline & BRASIL T PAR & $-9,479$ & 0,000 & & MARCOPOLO & $-8,230$ & 0,000 \\
\hline & BRASIL TELEC & $-10,262$ & 0,000 & & NET & $-3,869$ & 0,000 \\
\hline & BRASKEM & $-8,639$ & 0,000 & & SARAIVA LIVR & $-11,092$ & 0,000 \\
\hline & ELETROBRAS & $-11,332$ & 0,000 & & SUZANO PETR & $-12,000$ & 0,000 \\
\hline & CESP & $-9,665$ & 0,000 & \multirow{6}{*}{ 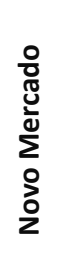 } & BRASIL & $-3,719$ & 0,000 \\
\hline & CEMIG & $-4,412$ & 0,000 & & SABESP & $-4,479$ & 0,000 \\
\hline & TRAN PAULIST & $-11,992$ & 0,000 & & EMBRAER & $-6,575$ & 0,000 \\
\hline & VALE R DOCE & $-12,014$ & 0,000 & & ETERNIT & $-1,080$ & 0,280 \\
\hline & CONFAB & $-1,751$ & 0,080 & & LIGHT S/A & $-0,359$ & 0,719 \\
\hline & DURATEX & $-12,016$ & 0,000 & & TRACTEBEL & $-9,070$ & 0,000 \\
\hline
\end{tabular}

Fonte: elaborado pelos autores.

Pelo quadro 8 , observa-se que a maior parte das empresas apresenta estatística $Z$ significante estatisticamente em nível de $5 \%$. Assim, para estas pode-se rejeitar a hipótese nula de que não houve alteração nas médias. Isso significa que tais empresas, no intervalo de tempo do estudo, apresentaram diferenças significativas em termos de risco, o qual foi medido pelo desvio-padrão dos retornos.

O teste de Wilcoxon realizado para o beta indica que apenas dois ativos não apresentam diferença significativa, ou seja, o beta de aproximadamente $96 \%$ dos ativos apresentou-se diferente dada a adesão aos níveis de governança corporativa.

Quadro 9: Teste de Wilcoxon para betas

\begin{tabular}{|l|c|c|c|c|c|c|c|}
\hline & Empresa & $Z$ & Prob $\left(Z>Z_{0}\right)$ & & Empresa & $Z$ & Prob $\left(Z>Z_{0}\right)$ \\
\hline
\end{tabular}




\begin{tabular}{|c|c|c|c|c|c|c|c|}
\hline \multirow{11}{*}{$\begin{array}{l}z \\
0 \\
-1 \\
\frac{1}{0} \\
\frac{2}{z}\end{array}$} & BRADESCO & $-8,366$ & 0,000 & \multirow{12}{*}{$\begin{array}{l}z \\
a \\
-1 \\
\bar{a} \\
\frac{2}{z}\end{array}$} & GERDAU & $-2,363$ & 0,018 \\
\hline & ITAUBANCO & $-3,546$ & 0,000 & & IOCHP-MAXION & $-11,888$ & 0,000 \\
\hline & BRADESPAR & $-8,325$ & 0,000 & & ITAUSA & $-4,887$ & 0,000 \\
\hline & BRASIL T PAR & $-8,087$ & 0,000 & & KLABIN S/A & $-9,403$ & 0,000 \\
\hline & BRASIL TELEC & $-12,014$ & 0,000 & & GERDAU MET & $-10,735$ & 0,000 \\
\hline & ELETROBRAS & $-10,086$ & 0,000 & & RANDON PART & $-4,437$ & 0,000 \\
\hline & CESP & $-11,957$ & 0,000 & & SADIA S/A & $-11,632$ & 0,000 \\
\hline & CEMIG & $-3,800$ & 0,000 & & SUZANO PAPEL & $-9,706$ & 0,000 \\
\hline & TRAN PAULIST & $-5,414$ & 0,000 & & ULTRAPAR & $-7,571$ & 0,000 \\
\hline & VALE R DOCE & $-12,016$ & 0,000 & & UNIBANCO & $-1,293$ & 0,196 \\
\hline & UNIBANCO & $-4,427$ & 0,000 & & UNIPAR & $-10,713$ & 0,000 \\
\hline \multirow{13}{*}{ 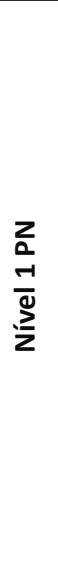 } & ARACRUZ & $-6,131$ & 0,000 & & VCP & $-7,101$ & 0,000 \\
\hline & ITAUBANCO & $-11,829$ & 0,000 & \multirow{6}{*}{ 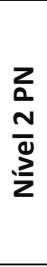 } & CELESC & $-9,169$ & 0,000 \\
\hline & BRADESPAR & $-10,799$ & 0,000 & & ELETROPAULO & $-6,803$ & 0,000 \\
\hline & BRASIL T PAR & $-3,693$ & 0,000 & & MARCOPOLO & $-7,576$ & 0,000 \\
\hline & BRASIL TELEC & $-3,746$ & 0,000 & & NET & $-7,673$ & 0,000 \\
\hline & BRASKEM & $-2,176$ & 0,030 & & SARAIVA LIVR & $-8,258$ & 0,000 \\
\hline & ELETROBRAS & $-10,944$ & 0,000 & & SUZANO PETR & $-12,014$ & 0,000 \\
\hline & CESP & $-10,896$ & 0,000 & \multirow{6}{*}{ 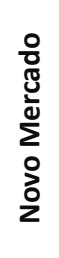 } & BRASIL & $-12,016$ & 0,000 \\
\hline & CEMIG & $-2,104$ & 0,035 & & SABESP & $-0,008$ & 0,994 \\
\hline & TRAN PAULIST & $-11,947$ & 0,000 & & EMBRAER & $-11,672$ & 0,000 \\
\hline & VALE R DOCE & $-12,016$ & 0,000 & & ETERNIT & $-5,275$ & 0,000 \\
\hline & CONFAB & $-11,530$ & 0,000 & & LIGHT S/A & $-4,873$ & 0,000 \\
\hline & DURATEX & $-12,016$ & 0,000 & & TRACTEBEL & $-12,016$ & 0,000 \\
\hline
\end{tabular}

Fonte: elaborado pelos autores.

A partir das premissas do artigo, e considerando os resultados para as variáveis beta e desvio, pode-se confirmar um dos benefícios afirmados pela BM\&F BOVESPA para as empresas que decidem aderir aos níveis de governança corporativa, o qual é a redução do risco. Isso pode ser afirmado pelos sinais das estatísticas Z obtidas no teste de Wilcoxon, tanto para desvio quanto para beta. Esse resultado não está coerente com Macedo, Mello e Tavares Filho (2006). Alguns aspectos metodológicos podem explicar as diferenças dos resultados como: i) Macedo, Mello e Tavares Filho (2006) usaram apenas as empresas do Nível 1; ii) os referidos autores consideraram alguns dados de retorno, como missing values, e excluíram da análise estatística, dado a baixa liquidez; iii) os betas usados como proxy de risco foram calculados de forma a representar o período de estudo (dois anos).

Em função dos resultados obtidos para os testes paramétricos e não paramétrico, não se rejeita $\mathrm{H}_{0,1}$ e conclui-se que o retorno das empresas que aderiram aos NDGC não apresenta diferenças antes e após a adesão aos níveis. Rejeita-se $\mathrm{H}_{0,2}$, que permite afirmar que o risco das empresas que aderiram aos NDGC apresenta diferenças antes e após a adesão aos níveis.

\section{CONSIDERAÇÕES FINAIS}

Com a necessidade de se adotar e implementar boas práticas de governança corporativa e com a intenção de atrair investimentos para as empresas, reduzir custos de capital, torná-las mais transparentes e seguras, do ponto de vista dos investidores, a BM\&F BOVESPA criou os Níveis Diferenciados de Governança Corporativa (Nível 1, Nível 2 e Novo Mercado). Esses níveis possuem certas exigências que as empresas devem cumprir de forma a atingir os objetivos 
almejados pela adoção de tais práticas.

Nesse cenário, verificou-se que muitas pesquisas procuraram relacionar a adoção dessas boas práticas, assim como a maior evidenciação das companhias, com a redução do custo de capital, do risco e do aumento do retorno das firmas. Porém, a maioria dos estudos não analisa, concomitantemente, o risco e o retorno.

Em função disso, com a intenção de contribuir para os estudos na área "Mercado de Capitais e Governança Corporativa", e verificar se os benefícios admitidos pela BM\&F BOVESPA quando as empresas aderem aos NDGC estão sendo alcançados, buscou-se verificar se o risco e o retorno das empresas que passam a cumprir as exigências de tais níveis tiveram modificações após a adesão. Dessa forma, foi feita uma análise com uma janela de 252 dias antes e após a data de adesão das empresas.

Como resultado, esperava-se certa coerência, ou seja, se os testes de retorno não indicassem mudanças significativas, os testes de desvio e beta (ou seja, risco) também não deveriam apresentar, ideia alicerçada na teoria de Markowitz (1952). Porém, não foi o que ocorreu no estudo.

De modo geral, os resultados encontrados no período, para o número de empresas analisadas e em função da metodologia empregada, não indicaram mudanças estatisticamente significantes antes e após a adesão, quanto ao retorno, o que não permite rejeitar a hipótese $\mathrm{H}_{0,1}$. Esse resultado indica que o mercado não percebeu a adesão das empresas aos níveis de governança como um evento que justificasse um retorno maior.

Por outro lado, os resultados dos desvios e dos betas apresentaram diferenças estatisticamente significantes, ou seja, foi possível rejeitar $\mathrm{H}_{0,2}$. Isso foi confirmado pelo teste paramétrico de médias emparelhadas, que foi aplicado em menos da metade da amostra, e também pelo teste não paramétrico de Wilcoxon, que permitiu considerar todos os ativos.

\subsection{Limitações e Recomendações de Estudo}

A adesão aos níveis é uma tentativa de sinalizar ao mercado maior segurança para o investidor, comparando-se com as empresas do segmento tradicional. Portanto, seria interessante realizar um teste que apontasse o sentido da variação da proxy de risco, o que pode ser um complemento para estudos futuros.

Como sugestão para pesquisas futuras, outros estudos poderiam trabalhar com um prazo de análise maior, bem como utilizar outras formas de cálculo de risco, ou diferentes métodos estatísticos. 


\section{REFERÊNCIAS}

AGUIAR, A. B.; CORRAR, L. J.; BATISTELLA, F. D. Adoção de práticas de governança corporativa e o comportamento das ações na Bovespa: evidências empíricas. Revista de Administração. v. 39, n.4, p.338-347, out./ nov./dez. 2004.

ALENCAR, R. C.; LOPES, A. B. Custo do Capital Próprio e Nível de Disclosure nas Empresas Brasileiras. In: Congresso USP de Controladoria e Contabilidade, 5, 2005, São Paulo- SP. Anais... São Paulo: FEA/USP, 2005.

ANDRADE, A.; ROSSETTI, J. P. Governança Corporativa. Fundamentos, Desenvolvimento e Tendências. São Paulo: Atlas, 2004.

ASSAF NETO, A. Contribuição ao estudo da avaliação de empresas no Brasil: uma aplicação prática. Ribeirão Preto: 2003. 202f. Tese (Livre Docência). Faculdade de Economia, Administração e Contabilidade de Ribeirão Preto - FEA-RP/USP, São Paulo, 2003.

BATISTELLA, F. D. et al. Retorno das Ações e Governança Corporativa: um estudo de eventos. In: Congresso USP de Controladoria e Contabilidade, 4, 2004, São Paulo- SP. Anais... São Paulo: FEA/USP, 2004.

BOTOSAN, C. A. Disclosure Level and the Cost of equity capital. The Accounting Review, v.72, n. 3, p. 323-350, 1997.

BOTOSAN, C. A.; PLUMLEE, A. M. A Reexamination of Disclosure Level and the Expected Cost of Equity Capital. Journal of Accounting Research, v.40, n.1, p.21-40, 2002.

BUSHMAN, R. et alli. What determines corporate transparency? Working Paper, University of Chicago, September 2001.

CAMARGOS, M. A.; BARBOSA, F. V. Evidência Empírica do Impacto da Adesão aos Níveis Diferenciados de Governança Corporativa sobre o Comportamento das Ações na Bovespa.
In: ENCONTRO DA ANPAD, 30, 2006, SalvadorBA. Anais... Salvador: Encontro da Associação Nacional de Pós-Graduação e Pesquisa em Administração, 2006.

CARDOSO, D. Correlacionando o Beta do Modelo CAPM- Capital Asset Princing Model com as Variáveis do Modelo Fleuriet: uma análise da siderúrgica Belgo Mineira In: Encontro da ANPAD, 24, 2000, Florianópolis-SC. Anais... Florianópolis: Encontro da Associação Nacional de Pós-Graduação e Pesquisa em Administração, 2000.

CARVALHO, A. G. Governança Corporativa no Brasil em Perspectiva. Revista de Administração, São Paulo, v. 37, n. 3, p. 19-32, jul/set. 2002.

COLLIS, J.; HUSSEY, R. Pesquisa em Administração: um guia prático para alunos de graduação e pós-graduação. 2 ed. Porto Alegre: Bookman, 2005.

DIAMOND, D.; VERRECCHIA, R. Disclosure, Liquidity, and the Cost of equity capital. The Journal of Finance, v. 46, n. 4, p.1327-1359, 1991.

FÁVERO, L. P.; BELFIORE, P.; SILVA, F. L. S.; CHAN, B. L. Análise de Dados: modelagem multivariada para tomada de decisões. Rio de Janeiro: Elsevier, 2009.

FRANCIS, J. R.; KHURANA, I. K.; PEREIRA, Raynolde. Disclosure Incentives and Effects on Cost of Capital around the World. The Accounting Review, v.80, n.4, p.1125-1162, 2005.

GODE, D.; MOHANRAM, P. What affects the implied cost of equity capital ? New York University Paper, p.1-30, 2001.

HAIL, L. The Impact of Voluntary corporate disclosures on the ex-ante cost of capital for Swiss firms. The European Accounting Review, v. 2 , n. 4, p. 741-773, 2002.

HEALY, P.; HUTTON, A.; PALEPU, K. Stock 
Performance and Intermediation Changes Surrounding Sustained Increases in Disclosure, Contemporary Accounting Research, v. 16, n. 3, Fall 1999, p. 485-520.

HILLBRECHT, R. Economia Monetária. São Paulo: Atlas, 1999.

JENSEN, M.; MECKLING, W. H. Theory of the firm: managerial behavior, agency costs and ownership structure. Journal of Financial Economics, Amsterdã, v. 3, n. 4, p. 305-360, oct.1976.

KITAGAWA, C. H.; GODOY, C. R.; ALBUQUERQUE, A. A.; CARVAlHo, F. L. Estudo Empírico sobre o Comportamento do Custo de Capital Próprio das Empresas Listadas nos Níveis 1 e 2 de Governança Corporativa da Bovespa. In: ENCONTRO DA ANPAD, 31, 2007, Rio de Janeiro. Anais... Rio de Janeiro: Encontro da Associação Nacional de Pós-Graduação e Pesquisa em Administração, 2007.

LAMBERT, R.; LEUZ, C.; VERRECCHIA, R. E. Accouting Information, Disclosure and the Cost of Capital. Journal of Accounting Research, v. 45, n. 2, p. 385-420, 2007.

LANZANA, A. P. Relação entre Disclosure e Governança Corporativa das Empresas Brasileiras. São Paulo, 2004. Dissertação (Mestrado em Administração) - Faculdade de Economia, Administração e Contabilidade, Universidade de São Paulo.

MACEDO, F. Q.; MELLO, G. R.; TAVARES FILHO, F. Adesão ao Nível 1 de Governança Corporativa da Bovespa e a Percepção de Risco e Retorno das Ações pelo Mercado. In: Congresso USP de Controladoria e Contabilidade, 6, 2006, São Paulo- SP. Anais... São Paulo: FEA/USP. p. 1-13.

MALACRIDA, M. J. C.; YAMAMOTO, M. M. Governança Corporativa: nível de evidenciação das informações e sua relação com a volatilidade das ações do Ibovespa. Revista de Contabilidade e Finanças. ed. comemorativa, set. 2006.
MARKOWITZ, H. Portfolio Selection. The Journal of Finance. v.7, n.1, 77-91, mar. 1952.

MARTINS, V. A.; SILVA, R. L. M.; NARDI, P. C. C. Governança Corporativa e Liquidez das ações. In: ENCONTRO DA ANPAD, 30, 2006, Salvador. Anais... Salvador: Encontro da Associação Nacional de Pós-Graduação e Pesquisa em Administração, 2006.

NAKAMURA, W. T.; GOMES, E. A.; ANTUNES, M. T. P.; MARÇAL, E. F. Estudos sobre os Níveis de Disclosure Adotados pelas Empresas Brasileiras e seu Impacto no Custo de Capital. In: ENCONTRO DA ANPAD, 30, 2006, Salvador. Anais... Salvador: Encontro da Associação Nacional de Pós-Graduação e Pesquisa em Administração, 2006.

OKIMURA, R. T. Estrutura de Propriedade, Governança Corporativa, Valor e Desempenho das Empresas no Brasil. 2003. 120f. Dissertação (Mestrado) - Faculdade de Economia, Administração e Contabilidade da Universidade de São Paulo, São Paulo, 2003.

PEDREIRA, E. B.; SANTOS, J. O. Análise da Relação Entre o Índice de Governança Corporativa, Preço das Ações e Desempenho dos Três Principais Bancos Privados Brasileiros. In: Congresso USP de Controladoria e Contabilidade, 6, 2006, São Paulo- SP. Anais... São Paulo: FEA/USP, 2006.

RABELO, S. S. T.; ROGERS, P.; RIBEIRO, K. C. S.; MENDES-DA-SILVA, W. Performance das Melhores Práticas de Governança Corporativa no Brasil: um estudo de carteiras. In: ENCONTRO DA ANPAD, 31, 2007, Rio de Janeiro. Anais... Rio de Janeiro: Encontro da Associação Nacional de Pós-Graduação e Pesquisa em Administração, 2007.

ROSS, S. A.; WESTERFIELD, R. W.; JAFFE, J. F. Administração Financeira. Tradução Antonio Zorato Sanvicente. São Paulo: Atlas, 1995.

SCHADEWITZ, H. J.; BLEVINS, D. R. Major Determinants of Interim Disclosures in am 
emerging market. American Business Review, n. 16, p. 41-55, jan., 1998.

SIRQUEIRA, A. B.; KALATZIS, A. E. G.; TOLEDO, F. M. B. Boas Práticas de Governança Corporativa e Otimização de Portfólio. Revista da Anpec, n.1, v.8. jan. 2007.

TOLEDO, M. M.; PAMPLONA, E. O. Avaliação do Risco Sistemático do Setor Bancário. In: ENEGEP, 24, 2006, Fortaleza. Anais... Fortaleza: Encontro Nacional de Engenharia de Produção, 2006.

TRIOLA, M. F. Introdução à Estatística. 7 ed. Rio de Janeiro: LTC, 1998.

VASCONCELLOS, P. C. Governança corporativa diz respeito à criação de valor. Revista RI Relações com Investidores. n. 52, p.19-20, jun. 2002. 